\title{
HORROR NOIRE: A REPRESENTAÇÃO NEGRA NO CINEMA DE TERROR
}

\author{
HORROR NOIRE: BLACKS IN AMERICAN HORROR \\ FILMS FROM THE 18905 TO PRESENT
}

Daniel Lucas de Medeiros'

1 Graduado em Comunicação Social - Cinema e Vídeo, especialista em Artes Visuais - Cultura e Criação, mestre em Ciências da Linguagem pela Universidade do Sul de Santa Catarina e atualmente cursa o doutorado, também em Ciências da Linguagem, tendo como objeto de pesquisa o cinema de terror. Bolsista CAPES. 
RESUMO (RESENHA): COLEMAN, Robin R. Means. Horror noire: a representação negra no cinema de terror. Tradução: Jim Anotsu. Rio de Janeiro: Darkside Books, 2019. 464 p.

PALAVRAS-CHAVE: Cinema; Terror; Horror; Representação negra.

ABSTRACT (REVIEW): COLEMAN, Robin R. Means. Horror noire: blacks in American horror films from the 1890s to present. Routledge, 2011. 298 p.

KEYWORDS: Cinema, Terror, Horror, Black representation. 
Escrito por Robin R. Means Coleman, o livro Horror noire: a representação negra no cinema de terror apresenta uma análise histórica da cultura negra no cinema de terror norte-americano, abordando temas como o apagamento da presença da pessoa negra nos filmes, a criação e a perpetuação de estereótipos e os movimentos de resistência visando a uma melhor representação. É uma obra de grande apelo acadêmico (tanto para os estudos sobre raça quanto para os estudos sobre cinema e sobre terror) e popular. O livro é fruto de uma extensa pesquisa realizada pela autora. Coleman trabalhou como professora adjunta no Departamento de Estudos da Comunicação e no Centro de Estudos Afro-americanos e Africanos da Michigan University. Atualmente, ela dá aula no Departamento de Comunicação da Texas A\&M University, onde também é vice-presidente e reitora adjunta para a diversidade. Seus trabalhos anteriores incluem o livro African American viewers and the Black situation comedy: situating racial humor (1998), no qual examina a representatividade negra na comédia, além de diversos artigos sobre mídia e raça. Ela também foi roteirista e produtora executiva de um documentário baseado no livro Horror noire.

Horror noire: a representação negra no cinema de terror foi originalmente publicado em 2011, mas chegou ao Brasil apenas em 2019. A distância temporal é significativa, uma vez que a escrita de Coleman precede o lançamento do filme Corra! (Get out, 2017), produção norte-americana do gênero de terror escrita e dirigida por Jordan Peele. A importância do filme para futuros estudos sobre raça e sobre terror é tamanha que esta edição nacional inclui uma introdução escrita por Ashlee Blackwell (produtora do documentário), falando especificamente sobre a obra de Jordan Peele. Ao examinar o livro, portanto, é importante observar essa visão calcada em uma realidade anterior a Corra! e às mudanças iniciadas por esse filme.

Estruturando seu estudo histórico em divisões através das décadas, Coleman guia a sua análise pela diferença entre o que ela chama de filmes de terror "com negros" e "filmes negros" de terror. Para a autora, filmes de terror "com negros" são produções de grandes estúdios, normalmente realizadas por pessoas não negras, nas quais os interesses e a representação da população negra não fazem parte dos propósitos dos filmes. Os "filmes negros" de terror seguem muitos dos mesmos tropos comuns ao gênero, mas também são filmes raciais, ou seja, são produções que representam 
a cultura e a população afro-americana e que priorizam o interesse dessa população (COLEMAN, 2019). Em sua maioria, "filmes negros" de terror são produzidos por pessoas negras, mas isso não é uma regra - Um vampiro no Brooklyn (Vampire in Brooklyn, 1995, direção de Wes Craven) e Bem-amada (Beloved, 1998, direção de Jonathan Demme) são dois exemplos apresentados de "filmes negros" de terror dirigidos por pessoas brancas.

No primeiro capítulo, intitulado "Pré-1930: o nascimento do bicho-papão negro no imaginário", a autora avalia as produções documentais e ficcionais realizadas nas primeiras décadas da história do cinema. Embora não pertençam ao gênero de terror, tais filmes estabeleceram a fundação para as narrativas preconceituosas perpetuadas através das décadas. Pelas lentes do homem branco, o negro era mostrado como o Outro, alguém cujos "hábitos mais mundanos precisavam ser documentados e exibidos como se os negros fossem animais em um zoológico." (COLEMAN, 2019, p. 60-61). Coleman também explora o clássico infame $O$ nascimento de uma Nação (The birth of a Nation, 1915), destacando a maneira como o filme de D. W. Griffith retratou o homem negro não apenas com um vilão, mas como um monstro altamente sexualizado, uma fonte de perigo para as donzelas brancas. O nascimento de uma $\mathrm{Na}$ ção foi responsável por transformar o homem negro em uma fonte de perigo dentro do cinema. "A negritude foi efetivamente transformada, e o negro se tornou uma das criaturas mais terríveis e temidas de todas." (COLEMAN, 2019, p. 68)

O "perigo sexual" representado pela figura do homem negro se manteve na década seguinte, embora o enfoque seja diferente. No capítulo "1930 - Febre da selva: um romance de horror", a autora detalha a evolução da abordagem racista, desta vez aproximando o homem negro da figura do animal. Coleman destaca dois filmes que popularizaram essa aproximação: King Kong (1933, direção de Merian C. Cooper e Ernest B. Schoedsack) e Ingagi (1930, direção de William Campbell). Em King Kong, a criatura do título é apresentada como um ser que vive nas profundezas de uma ilha e representa uma ameaça à pureza das donzelas brancas, assim como no filme de Griffith. Ingagi parte de uma premissa similar. O filme mostra uma expedição ao Congo Belga, na qual um explorador se depara com uma tribo de mulheres adoradoras de gorilas. O teor da "ameaça" sexual representada pelo animal está presente em ambos 
os filmes. Coleman também explica que a selvageria da floresta era contraposta pela docilidade do ambiente doméstico. Quando os filmes mostravam a pessoa negra dentro de casa, a abordagem era cômica. "Essa representação se alinhava às representações seguras, alegres, subservientes e dessexualizadas de filmes como ... E o vento levou, que remontavam a um período mais estável e ordeiro da história americana." (COLEMAN, 2019, p. 93-94) A autora conclui que a década de 1930 serviu para estabelecer o perigo da "ameaça negra" como aquela que vinha de fora. O perigo era representado por uma figura selvagem oriunda das profundezas das florestas africanas. As donzelas brancas estariam seguras, desde que permanecessem dentro de casa.

Subserviência e/ou estereótipo pareciam ser as únicas representações possíveis dentro do cinema de terror. Na intenção de mudar esse cenário desfavorável, na década de 1940 o ator e cineasta Spencer Williams se reuniu com representantes do terror negro com o objetivo de propor soluções para essa (falta de) representação. Como as mudanças não vieram na velocidade esperada, Williams tomou para si a responsabilidade. Ele passou a escrever e, eventualmente, dirigir "filmes negros" de terror. Graças a esforços como esse, houve uma mudança - ainda que pequena - na representação da cultura negra, conforme é discutido no capítulo "1940 - Bandidos aterrorizantes e miseráveis menestréis". Paralelamente aos esforços de Williams, Hollywood continuou a perpetuar os estereótipos. Até a religiosidade presente nos "filmes negros" de terror foi transformada em motivo de perigo. O vodu, religião de origem africana, foi vista como motivo de temor pela população branca. Esse perigo foi simbolizado pela figura do zumbi, um corpo inerte controlado por magia. Mais do que o medo do desconhecido, o monstro aqui tem uma relação direta com a época. Para a autora, "os zumbis se tornaram a representação de um tipo de controle mental e social antidemocrático que regimes mais fascistas empregariam" (COLEMAN, 2019, p. 158).

No capítulo intitulado “1950, 1960 - Invisibilidade negra, ciência branca e uma noite com Ben", Coleman explora a ausência negra do cinema de terror nas décadas de 1950 e 1960, contrapondo-a à presença marcante de Ben, protagonista do filme $A$ noite dos mortos-vivos (Night of the living dead, 1968, direção de George A. Romero). $\mathrm{O}$ contraponto se faz necessário, uma vez que os filmes dessa época voltaram seus olhares para a África e o Caribe como fonte de terror, ao mesmo tempo que conflitos sociais 
reais ocorriam dentro do território americano (COLEMAN, 2019). O racismo dentro dos Estados Unidos era um assunto enterrado, até sair do seu túmulo com o lançamento de A noite dos mortos-vivos. A obra narra a história de um grupo de pessoas escondido em uma casa, tentando se proteger de um ataque de zumbis. Uma das mudanças propostas pelo filme se dá na figura do monstro. "A noite dos mortos-vivos não acusa a negritude do mal que está acontecendo. Os zumbis não são negros e não surgem de lugares negros com a África, o Caribe ou algum pântano de Louisiana, nem se levantam como resultado de algum ritual vodu." (COLEMAN, 2019, p. 185-186) O grande destaque, porém, se dá pela figura do protagonista Ben. Interpretado pelo ator negro Duane Jones, o personagem é o líder do grupo e enfrenta a resistência de outras pessoas (brancas), incomodadas com o seu protagonismo. Ao final do filme, Ben, a única pessoa a sobreviver aos ataques zumbis durante a noite, é morto por um grupo de caçadores (também brancos) que o confunde com um morto-vivo. Para Coleman, a morte do protagonista é um dos momentos mais chocantes e realistas do filme. A autora ainda destaca a importância não apenas de Ben como de outros personagens negros ao longo da carreira do cineasta George A. Romero. Segundo ela, os personagens negros nos filmes de Romero "são autoconscientes de suas identidades, e, enquanto buscam sobreviver entre os demais, eles não passam necessariamente uma mensagem de integração, mas de coexistência - uma diferença sutil, mas importante" (COLEMAN, 2019, p. 199).

Os conflitos sociais ocorridos ao longo dos anos 1960 tiveram consequências duradouras e foram refletidos na cinematografia da década de 1970. Isso é discutido mais a fundo no capítulo "1970 - Grite, branquelo, grite: retribuição, mulheres duronas e carnalidades". Ao longo desse capítulo, Coleman destaca a ascensão de um subgênero conhecido como blaxploitation, com produções voltadas para o público afro-americano. Eram filmes que traziam um discurso político de empoderamento negro, influenciando a produção de cinema de gênero naquela época. Segundo a autora, os filmes de terror comerciais mostram uma ameaça que se encerra quando a mocinha finalmente consegue matar o vilão. Já os "filmes negros" de terror revelavam que o mal que ameaça a população negra era muito mais duradouro, e persistia ao final. “Os filmes se esforçaram para revelar ao público que, para os negros, o horror (ou o monstro) estava localizado dentro da branquitude" (COLEMAN, 2019, p. 242). 
A mudança, novamente, não durou muito tempo. No capítulo seguinte, dedicado à década de 1980, Coleman explica como a produção de terror pareceu não ter aprendido nada com os anos pregressos. Intitulado "Nós sempre morremos primeiro: invisibilidade, segregação racial econômica e o sacrifício voluntário", o capítulo explica que a presença da pessoa negra nos filmes de terror nessa época serviu apenas como apoio para os personagens brancos. O negro era a pessoa que morria para provar (para o herói branco) que a situação era perigosa. A autora também destaca que houve uma mudança na representação do vilão. Com a ascensão de franquias como Halloween, $A$ hora do pesadelo (A nightmare on Elm Street) e Sexta-feira 13 (Friday the 13th), o que se via era que "os monstros dos anos 1980 eram brancos, masculinos e suburbanos" (COLEMAN, 2019, p. 277). O terror suburbano apagou a presença negra.

A péssima representação dos anos 1980 foi compensada na década seguinte, conforme discutido no capítulo "1990 - Estamos de volta! A vingança e o terreno urbano”. Nessa época, “[o] negro estava em todos os lugares - em 'filmes negros' de terror e em filmes de terror 'com negros', filmes independentes e filmes hollywoodianos, em sucessos de bilheteria de alto orçamento e até em esforçados filmes de baixo orçamento que não passariam nos cinemas" (COLEMAN, 2019, p. 318). A autora explica ainda que o terror saiu dos subúrbios de cercas brancas e passou a se localizar nos guetos negros das cidades grandes. Assim como aconteceu com a religião na década de 1940, os guetos foram um tema presente tanto em filmes de terror "com negros" quanto em "filmes negros" de terror. E, assim como antes, a abordagem se diferia de filme para filme. “Em vários 'filmes negros' de terror, a área urbana era retratada como um lugar perigoso e problemático, mas que valia o esforço e mesmo a tentativa de limpeza" (COLEMAN, 2019, p. 283). Ao contrário disso, filmes de terror "com negros", como é o caso de O predador 2 - A caçada continua (Predator 2, 1990, direção de Stephen Hopkins), retrataram “a área urbana como os filmes das décadas de 1920 e 1930 mostravam as florestas da África - sedenta por sangue" (COLEMAN, 2019, p. 283).

A produção de "filmes negros" de terror se mostrou ainda mais significativa diante do desgaste sofrido do gênero, gerado pela excessiva onda de continuações de filmes das décadas passadas. Além disso, a evolução da tecnologia de vídeo e o crescimento de filmes produzidos diretamente para as locadoras abriram um espa- 
ço significativo. Nesse novo mercado, "[o] terror foi novamente confrontado com a proposta de atender a uma necessidade, e, em uma repetição das décadas de 1940 e 1970, todos os tipos de 'filmes negros' de terror entraram num sistema de produção rápido e barato" (COLEMAN, 2019, p. 319). Coleman conclui o seu livro com uma previsão para o novo século. Em uma afirmação hoje datada, ela diz que "o gênero de terror não está tentando inovar; em vez disso, está requentando terrores antigos de seu catálogo para reapresentá-los ao público. Em lugar de seguir a tendência de inovação, cineastas millennials estão preferindo fazer remakes" (COLEMAN, 2019, p. 321-322). O destaque dela é dado apenas aos "filmes negros" influenciados pela cultura do hip-hop, lançados em vídeo.

Coleman não contava, no entanto, com a revolução causada pelo lançamento e consagração de Corra! e a subsequente ascensão não apenas de filmes com temáticas sociais, mas também de uma maior representatividade da cultura negra dentro do cinema de terror. Abordando temas como a falácia da era "pós-racial”, Coleman adianta, mesmo sem saber, algumas das temáticas discutidas por Peele em seus filmes e até ensaia a (possível) revolução gestada atualmente, afirmando que "a eleição de Obama deve desafiar criadores de imagens a confrontar as realidades do século XXI, em que negros podem ser vistos habitando uma variedade de posições sociais e ideológicas" (COLEMAN, 2019, p. 343). Mas nem ela parecia saber a extensão dessa variedade.

Ao final, o livro nos mostra a construção e perpetuação de estereótipos e os movimentos de resistência ocorridos ao longo da história do cinema de terror. A análise de Coleman é qualitativa e quantitativa, trazendo à tona títulos pouco conhecidos e jogando uma nova luz sobre filmes mais conhecidos - como é o caso da leitura que ela faz do filme $O$ mistério de Candyman (Candyman, 1992, direção de Bernard Rose). Isso faz de Horror noire: a representação negra no cinema de terror uma obra essencial para os estudos do terror e da representação da cultura negra no cinema. 


\section{BIBLIOGRAFIA}

COLEMAN, Robin R. Means. Horror noire: a representação negra no cinema de terror. Tradução: Jim Anotsu. Rio de Janeiro: Darkside Books, 2019. 464 p. 